\title{
Política de Publicação
}

\section{Autoria, titulação e normas gerais:}

São aceitos trabalhos em que pelo menos um dos autores tenha o título de doutor. Mestrandos, mestres e doutorandos podem submeter artigos com a condição de que sejam co-autores com pesquisadores doutores. A comissão editorial entende que a supervisão de alunos deve ser explícita, e não deve ser tomada como coautoria. Artigos derivados de pesquisas de mestrado ou doutorado devem incluir o nome do orientador em nota de rodapé, e não como co-autor. Uma exceção é feita as resenhas, em que é permitido resenhas de doutorandos.

A - Artigo: Texto resultante de pesquisa (bibliográfica, documental, experimental...), preferencialmente concluída, destacando a fundamentação teóricometodológica, apresentando reflexão teórica que aprofunde um tema ou nova abordagem importante para o debate acadêmico na área de Letras e Linguística. $\mathrm{O}$ artigo deve apresentar procedimentos empregados na pesquisa e resultados alcançados - máximo 25 laudas, espaço simples.

B - Resenhas: Texto que apresente uma apreciação crítica de livros recém-editados nos campos de Letras e Literatura correspondente - máximo 08 laudas, espaço simples.

C- Entrevistas inéditas relacionados com o tema do número específico, máximo 25 laudas, espaço simples.

D - Os textos deverão ser digitados com a seguinte configuração: espaço simples, corpo 12, tipo Times News Roman, formato de papel A4, sem marcações de parágrafo.

E - A primeira lauda deve iniciar com o cabeçalho com o título do texto e sua versão para a língua inglesa (caso seja em Português). Deve ser deixado espaço interlinear branco entre o título e sua versão para a língua inglesa. Deve haver espaçamento entre todos os títulos de seção e o texto. O cabeçalho deve ser seguido pelo o resumo do artigo expressando, de forma clara, a ideia do trabalho. Caso o artigo seja em português, é preciso uma versão em inglês e português do resumo. F - As palavras-chave devem vir logo abaixo dos resumos. Essas devem representar o assunto do artigo e seguir o idioma do resumo. Ou seja, resumos em inglês são seguidos por palavras-chave em inglês, e resumos em português são seguidos por palavras-chave em português. Em ambos os casos, devem ser separadas por "ponto e vírgula" - máximo de 5 palavras-chave. 
G- As citações no corpo do texto deverão ser redigidas de acordo com o padrão estilístico correspondente a cada área: artigos, resenhas e entrevistas em inglês da área de Literatura devem obedecer às normas do MLA; artigos, resenhas e entrevistas em inglês da área de Linguística seguem as normas do APA; e artigos, resenhas e entrevistas em Português seguem as normas da ABNT.

$\mathrm{H}$ - O uso de notas, citações, gráficos, tabelas, figuras, quadros, fotografias, etc, deve ser limitado ao mínimo indispensável.

I- Recomenda-se incluir o(s) nome(s) da(s) pessoa(s) que de alguma maneira auxiliaram seja na coleta de dados, nas ilustrações, ou mesmo na utilização de laboratórios mencionando "AGRADECIMENTOS” antes das Referências.

J - Os originais não deverão ser paginados.

$\mathrm{K}$ - O autor deve informar a referência de toda informação não original, caso contrário é considerado plágio. A Revista Ilha do Desterro segue as diretrizes e recomendações propostas pelo CNPQ quando ao plágio e autoplágio, que define as seguintes modalidades de fraude ou má conduta em publicação:

Fabricação ou invenção de dados - consiste na apresentação de dados ou resultados inverídicos.

Falsificação: consiste na manipulação fraudulenta de resultados obtidos de forma a alterar-lhes o significado, sua interpretação ou mesmo sua confiabilidade. Cabe também nessa definição a apresentação de resultados reais como se tivessem sido obtidos em condições diversas daquelas efetivamente utilizadas.

Plágio: consiste na apresentação, como se fosse de sua autoria, de resultados ou conclusões anteriormente obtidos por outro autor, bem como de textos integrais ou de parte substancial de textos alheios sem os cuidados detalhados nas Diretrizes. Comete igualmente plágio quem se utiliza de ideias ou dados obtidos em análises de projetos ou manuscritos não publicados aos quais teve acesso como consultor, revisor, editor, ou assemelhado.

Autoplágio: consiste na apresentação total ou parcial de textos já publicados pelo mesmo autor, sem as devidas referências aos trabalhos anteriores. 


\section{LINHAS DE PESQUISA DO CURSO DE PÓS-GRADUAÇÃO EM INGLÊS E LITERATURA CORRESPONDENTE}

\section{LÍNGUA INGLESA E LINGÜÍSTICA APLICADA AO INGLÊS:}

- Análise do Discurso

- Aquisição de Língua Estrangeira

- Leitura em LE

- Tradução

\section{LITERATURAS DE LÍNGUA INGLESA:}

- LiteraturasdeLínguaInglesadoSéculoXIX à Contemporaneidade

- Teoria e Crítica Literária e Cultural: Literatura, Cinema e Teatro

\section{INFORMAÇÕES:}

Programa de Pós-Graduação em Inglês e Literatura Correspondente Centro de Comunicação e Expressão - UFSC

Caixa Postal 427

Campus Universitário - Trindade 88040-900 - Florianópolis - SC

Telefone (048) 3721-9455 - Fax (048) 3721 -9819

corseuil@cce.ufsc.br www.ilhadodesterro.ufsc.br 


\section{REVISTA ILHA DO DESTERRO}

Aquisição de números anteriores/Acquisition of single issues

From/De:

Name/Nome:

Address/Endereço

Zip Code/CEP: City/Cidade: State/Estado:

NÚMERO AVULSO R \$20,00

SINGLE ISSUE R \$20,00

( ) 50 EXPRESSION, IDENTITY AND SOCIETY

( ) 51 FILM BEYOND BOUNDARIES

( ) 52 CORPUS LINGUISTICS

( ) 53 METAPHOR IN LANGUAGE AND THOUGHT: CONTEMPORARY PERSPECTIVES

( ) 54 LITERATURAS DE LÍNGUA INGLESA: MEDIAÇÕES GLOBAIS/ LITERATURES IN ENGLISH: GLOBAL MEDIATIONS

( ) 55 ENGLISH INTERPHONOLOGY PERCEPTION, PRODUCTION AND EFFECT OF INSTRUCTION

( ) 56 POETICS AND OTHER DISCOURSES OF RESISTANCE IN CANADA

( ) 57 ON FOREIGN LAND: IDEOLOGIES AND TRAVEL DISCOURSE

( ) 58 CONTEMPORARY IRISH THEATRE ON FOREIGN LAND: IDEOLOGIES AND TRAVEL DISCOURSE

( ) 59 NEW PERSPECTIVES ON HISTORY THROUGH LITERATURE

( ) 60 RECENT DEVELOPMENTS IN SLA

( ) 61 SOUTH AFRICA: LITERATURE AND MEDIA

( ) 62 GOTHIC: NEW DIRECTIONS

( ) 63 THE NEUROSCIENCE OF READING

Anexar cheque nominal à Ilha do Desterro

Enclose International money order to Ilha do Desterro.

Enviar para/Send to:

REVISTA ILHA DO DESTERRO

Pós-Graduação em Inglês

Centro de Comunicação e Expressão - UFSC

Campus Universitário - Trindade

88040-900 - Florianópolis - SC 